\title{
小学数学教育教学要讲究方式方法
}

\author{
王正宏
}

甘肃省陇南市康县周家坝镇中心小学

DOI:10.32629/er.v3i4.2632

[摘 要] 小学数学教育是学生数学的启蒙阶段, 对学生日后的数学学习有着极大的影响, 教师在其中的作用也是极其重要的。本文通过教与学 的研究, 探讨如何在数学教学过程中, 找对的教学方式方法, 有效的调动学生的积极性和主动性, 从小培养小学生的创新能力。因此, 将抽象的数学 关系转化为学生生活中熟悉的事例,提高课堂的有效性,从而使儿童学得更主动。

[关键词] 小学; 数学; 教学; 方式方法

\section{1 提高数学教学方法之分析学生的全面实际情况}

教师只是学习的引导者, 学习的主体永远都是学生自己, 学习的过 程只有亲力亲为方能有所收获和进步, 所以, 在教学过程中, 教师要深入 了解学生的各方面问题和实际情况。学生的数学学习不是学生简单接受 知识的过程, 而是学生这个学习的主体在自身原有生活经验和知识基础 上主动建构的过程。作为教师, 要正确认识和全面把握学生原有的生活 经验和知识基础, 这是实现教学有效性的重要前提和必备条件。而要做 到这一点, 就非常的不容易。学生是一个个独立的个体, 他们的生活经验 和知识背景不尽相同, 要准确把握确非易事。但是, 相同年龄阶段的学生, 有着大致相同的年龄特征, 他们的认知能力, 个性特质、情感倾向、心理 特征大致相同。教师把握这些共同点, 是能够做到的。在小学数学教学 中, 有一种现象值得引起教师的重视, 那就是对学生的知识背景把握的 较准, 而对他们的生活经验却难以准确的把握。尤其是对每一个学生的 学习心理、学习品质、认知风格难以把握。这个问题已经成为制约教学 有效开展的重要因素。

\section{2 提高数学教学方法之合理地、正确地创设教学情境}

所谓教学情境是指教师在教学过程中创设的情感氛围。教学情境是课 堂教学的基本要素, 创设教学情境是教师的一项常规教学工作, 创设有价 值的教学情境则是教学改革的重要追求。数学教学是数学活动的教学, 是 师生之间, 学生之间交往互动与共同发展的过程。数学教学要求紧密联系 学生的生活实际, 从学生的生活经验和已有知识出发, 创设各种情境, 为学 生提供从事数学活动的机会, 激发对数学的兴趣, 以及学好数学的愿望。根 据小学生的认知规律、心理特点及教学内容创设良好的学习情境有助于 激发学生学习兴趣, 产生对新知识探究的需要。因此, 这个学习情境应该 是现实的、有意义的、有挑战性的。情境创设是联系数学与生活的纽带、 桥梁, 创设情境已成为教学活动中的一种潮流和时尚, 越来越得到老师 的重视。教师在引导学生学习圆的周长时, 可以让学生沿着自己的学具 圆的边缘摸一摸, 边摸边用自己的话说说什么是圆的周长, 然后用电脑 课件演示圆周轨迹并闪秌这个圆的周长。这样, 教师运用这个情境一下 子就使学生兴趣盘然地进入了自己的角色, 这不失为一个实效性较高的 情境设计。但是在课堂上创设情境的同时要注意情境设计的正确性, 不 可占据一堂课的过多时间, 更不能偏离了课堂教学内容。所以, 创设正确 的教学情境是尤为重要的。

\section{3 提高数学教学方法之积极培养学生发散思维}

小学生年龄小, 精力不集中, 思维十分活跃。但培养小学生的思维尤其 重要。思维的积极性、求异性、广阔性、联想性等发散思维的特征, 在数 学教学中有意识地抓住这些特性进行训练与培养, 既可提高学生的发散思 维能力, 又是提高小学数学质量的重要环节。美国心理学家吉尔福特认为: 发散思维与创造力有直接关系, 它可以使学生思维灵活, 能让学生丰富想 象, 积极探索求异, 坚持自己的独立见解。这就要求我们在课堂教学中, 善 于挖掘教材中蕴含的创造性因素。常言说教学有法, 但无定法, 教师要根据 教学内容不断变换角度, 充分利用学生的旧知识, 创设思维, 让学生自己去 发现问题、解决问题, 学会从不同的角度、不同的层次去思考问题, 解决问 题, 以培养学生发散性思维的能力, 发挥个性创造能力。然后教师的点拨尽 可能将已知信息沿着不同的途径向各种可能的方向扩散, 培养学生的发散 思维, 提升学生的创新能力。由于受传统环境影响, 我国的教师和家长在表 扬和鼓励学生上远远落后于西方国家, 为此我国的很多学生往往因为缺乏 鼓励和关注而丧失信心, 尤其是一些成绩稍差的学生, 更得不到教师应有 的关注, 为此, 在新课改下, 我们一定要多给学生一些鼓励, 培养学生发散 思维, 提高教学质量。我们这些小学教师要从培养学生的兴趣入手, 联系生 活实际学数学, 善于引导学生从不同的角度思考问题, 要善于变换题型, 变 式练习促进学生的思维, 让学生去思、去说、去做, 只有这样, 我们的学生 才会越来越聪明, 会思考、会做事、会生活。

\section{4 结束语}

任何事物的发展都需要创新, 小学数学教学也不例外, 创新教育也是 根据创新原理, 以培养学生具有一定的创新意识、创新思维、创新能力以 及创新个性为主要目标的教育理论和方法, 重在学生牢固、系统地掌握学 科知识的同时, 发展他们的创新能力。

[参考文献]

[1] 马翠平.浅谈小学数学研究性学习教学策略分析 [J]. 学周 刊,2018(35):58-59.

[2]陈琼兰.拨开教育理论神秘的面纱——读《现代中小学教学策略》 有感[J].北京教育(普教版),2017(12):87.

[3] 林冬兰.浅谈小学数学教学中的创新教育 [J]. 课程教育研 究,2017(06):116-117. 